Derecho y Realidad

Vol.13 - Núm. 26 • Julio-Diciembre de 2015

Págs.153-170 •ISSN:1692-3936

\title{
El paro nacional agrario de 2013 y la política agropecuaria 2006-2014*
}

\author{
The national agrarian strike of 2013 and \\ the agricultural policy 2006-2014
}

\author{
Froilán Campos Martínez**
}

\section{Resumen}

El objetivo general del presente trabajo fue analizar las condiciones y consecuencias del Paro nacional agrario de 2013 y la política agropecuaria 2006-2014, a través de un diagnóstico del sector agropecuario en Colombia en ese lapso, incluyendo los antecedentes (una mirada a las políticas económicas, neoliberalismo y apertura económica en el país) situación nacional actual, derechos del campesino aprobados recientemente, realidad agropecuaria del campesinado frente a los derechos humanos y el análisis de la jurisprudencia.

Se estudia lo atinente a la política agraria nacional y regional (planes de desarrollo, documentos Conpes), y cómo ha sido la política agraria en Boyacá

Fecha de aceptación:

Concepto de recepción: 27 de agosto de 2015

Fecha de aprobación: 15 de noviembre de 2015

* Este artículo estudia cuáles fueron las condiciones del paro agrario del 2013 y analiza las consecuencias con base en la situación actual, empalmándola con los derechos con que cuentan los campesinos en este momento.

** Abogado, especialista en Derecho Administrativo. Estudiante de Maestría en Derechos Humanos en la Universidad Pedagógica y Tecnológica de Colombia de Tunja. drcampos51@hotmail.com 
(caracterización del departamento y planes departamentales de desarrollo). Se confrontan los derechos humanos y política agraria: movimientos campesinos en Boyacá en la última década 2005-2015. El último aparte trata la situación agropecuaria de Boyacá y el paro agrario, con sus antecedentes (contenido o plataforma política de las reivindicaciones propuestas por el movimiento); dinámica del movimiento (cómo se desarrolló, quiénes participaron, para qué participaron, dónde se desarrolló el movimiento; repercusiones del movimiento campesino boyacense en el departamento y en el país (logros y movimientos), con los avances alcanzados (mesa regional agropecuaria: Boyacá, Cundinamarca y Nariño).

\section{Palabras clave}

Atraso, migración, pobreza, exclusión, luchas agrarias, tradición, subsistencia, política agropecuaria.

\section{Abstract}

The general objective of this article was to analyze the conditions and consequences of the 2013 national agrarian strike and the agricultural policy 2006-2014, through a diagnosis of the agricultural sector in Colombia, including the background (a look at economic policies, neoliberalism and economic liberalization in the country), current national situation, recently approved farmer rights, agricultural reality of the peasantry against human rights and analysis of jurisprudence. We study national and regional agricultural policy (development plans, Conpes documents). Human rights and agricultural policy are confronted: peasant movements in Boyacá in the last decade 2005-2015. The last paragraph treats the agricultural situation and agrarian strike in Boyacá, with their background (content or political platform of the claims proposed by the movement); dynamics of movement, who participated, why did they participate, where was the movement developed; impact of Boyacá peasant movement in the department and in the country (achievements and movements), the achieved advances (agricultural regional table: Boyacá, Cundinamarca and Nariño).

\section{Keywords}

Backwardness, migration, poverty, exclusion, agrarian strikes, tradition, subsistence, agricultural policy. 


\section{Sumario}

1. Desarollo

2. Conclusiones y referencias

\section{Método}

Sociológico

\section{Metodología}

Sociológica descriptiva y emperica de campo porque arroja resultados sobre los hechos descritos. 


\section{Introducción}

La importancia que ha tenido históricamente el sector agropecuario en la economía nacional al contribuir de manera significativa a la formación del capital nacional reflejado en PIB y al ser la despensa de la seguridad alimentaria para todos los ciudadanos, son hechos que han sido reconocidos en los planes de desarrollo nacionales para los años 2006-2018. Sin embargo, la constante del gobierno de turno y de los políticos es reprochar las manifestaciones campesinas por vías de hecho o diálogo, tratando de impedir la presencia política de este sector en la escena nacional.

La constante tensión entre Estado y campesinos en busca del reconocimiento de los derechos humanos, emerge por la situación de pobreza, abandono en que se encuentra el sector y el desacierto de los modelos de desarrollo implementados. Estas son algunas circunstancias que Ilevó al sector campesino a protestar con el paro nacional agrario del 19 al de agosto de 2013, para que el Gobierno nacional se percatara de la crisis agropecuaria y atendiera su pliego de peticiones con acciones concretas.

Superadas las vías de hecho, el Gobierno nacional abre las puertas instituyendo el denominado "Pacto Nacional por el Agro y el Desarrollo Rural ", como instrumento que permita diseñar una política de desarrollo rural, según las necesidades reales de los campesinos colombianos, es decir, que garantice los derechos humanos de los mismos y no según los intereses económicos de las multinacionales y entidades financieras, máxime cuando se reconoce por el Estado que la naturaleza misma de las actividades agropecuarias comporta un alto índice de riesgo en sus resultados para asegurar condiciones favorables que permitan el éxito de las cosechas y un positivo precio en términos rentables.

En este contexto, es pertinente asumir con responsabilidad estos momentos históricos para reflexionar constantemente en la búsqueda de soluciones para el campo colombiano y boyacense, que no es más que la lucha por la dignificación del trabajo de los campesinos.

Por lo anterior, se describen en primera instancia, los ejes de las políticas de desarrollo agrario durante los períodos 2006-2010, 2011-2014 y 2015-2018 y a través de qué estrategias se han pretendido lograr las referidas propuestas. En segundo lugar, se aborda el análisis de la política agraria, implementada en los planes de desarrollo referidos con el objeto de contrastarlas con las pretensiones del pliego de condiciones del paro agrario e incursionar en las falencias que median entre estas y las necesidades y expectativas de los campesinos que generaron el paro agrario de 2013, no sin antes hacer una descripción fenomenológica de la dinámica de los movimientos campesinos de la última década y como conclusión intentar generar una agenda de lucha para dignificar el trabajo de sector. 
El punto de partida de la investigación son los planes de desarrollo de los períodos 2006-2010, 2010-2014 y 2015-2018 en relación con la estrategia agraria y la estrategia global desarrollada en cada plan, para finalmente llegar a la política pública establecida en el departamento de Boyacá durante este mismo período.

La presente investigación es importante, porque se analizan problemas de actualidad nacional, confirmados por el Departamento de Planeación Nacional, con gran connotación para las familias campesinas que requieren una atención urgente para solucionarlos, donde la aprobación de los derechos de los campesinos se convierte en una herramienta para que les sean amparados sus derechos fundamentales, especialmente el de la subsistencia que reúne a la mayoría de los que están contemplados en la Carta Política.

En ese orden de ideas, está presente la jurisprudencia de la Corte Constitucional y del Consejo de Estado, donde la primera con sus sentencias hitos y unificadas, ha creado una línea que refuerza la necesidad de aplicar con las herramientas que se tienen el derecho ambiental.

Respecto al papel que asumen los egresados de la Maestría de Derechos Humanos de la UPTC (2015), se tiene el compromiso misional de ser formados "desde una perspectiva de teoría crítica de los derechos humanos y de una relación teoría-practica comprometida con la realidad nacional y basada en una investigación científica de alta calidad que contribuya con la construcción de una fundamentación de los derechos humanos en el contexto de América Latina". Lo que hace más grande el compromiso adquirido, porque imprime mayores deberes para escrutar en el derecho indígena y enriquecerlo junto con el ambiental.

\section{Desarrollo}

Respecto al diagnóstico del sector agropecuario en Colombia en el período 20062015, para Robledo $(2015$, p. 1) las dificultades no se iniciaron con la apertura económica de 1990, porque esta se venía aplicando desde años anteriores, como en 1935, 1954, 1966 y entre 1973 y 1982, situación que se agravó aún más porque el Estado, representado en varios presidentes, se propuso importar productos agrícolas, sin medir primero la necesidad, con fundamento en la oferta de la cosecha que en ese mismo momento se estaba recolectando.

Actualmente (2015), la apertura no ha concluido y las consecuencias de su aplicación no solo saltan a la vista, sino que se pueden comprobar con algunos indicadores y cifras que se muestran al final del presente capítulo y en el siguiente.

En ese orden de ideas, Garay (2009) coincide con Robledo respecto a los resultados 
nefastos que generaron las políticas neoliberales y aperturistas en el país, que para enfrentarlas el país no estaba, ni está preparado. Sin embargo, no se aprende de los errores cometidos y se sigue insistiendo en su aplicación, en vez de reorientar las medidas, ajustarlas para el logro del beneficio del sector agropecuario, economía nacional y superar en cierta forma las deficiencias que en materia social presenta el país.

La Misión para la Transformación del Campo Colombiano, coordinada por el DNP, afirma que diez principales cuellos de botella frenan el desarrollo rural y agropecuario colombiano (pobreza y servicios públicos; envejecimiento y migración; ingresos insuficientes; caos en la propiedad; rezago y tradición; monoexportadores: café; política pública incipiente; limitaciones en la comercialización; ausencia de financiación y desastres naturales e imprevistos), que al confrontarlos con el derecho de los campesinos aprobado recientemente por la ONU y con las grandes necesidades que surgieron del reciente paro agrario, se traza una senda de soluciones que aunadas a la línea jurisprudencial, generan expectativas de cambio, pero a la vez de problemas, porque el Estado, como en otras oportunidades, va dilatar las respuestas (DNP, 2015).

En ese orden de ideas, la Declaración Internacional de los Derechos de los Campesinos, que se cataloga novedosa, reciente y revolucionaria, porque ya está generando reacciones del campesinado por la protección de sus derechos (Cundinamarca y Santander del Sur), contempla catorce artículos, de los cuales solo el primero se refiere a la definición del término y sus acepciones, sin embargo, es conveniente confrontar su contenido con la realidad nacional y regional. Dada su aprobación en 2013, no existe jurisprudencia que se ampare en ellos, porque las más recientes de la Corte Constitucional y del Consejo de Estado, son anteriores a esta fecha.

Si se comparan estos derechos con los graves problemas que enfrenta el campesinado colombiano, al igual que con las razones que han llevado a protestas reiteradas, el contenido de los mismos le da total razón para que sean reivindicados, y su aplicación va a generar un nuevo caos, porque los empresarios, terratenientes, transnacionales, ante un Estado permisivo, no van a permitir que les sean quitadas sus propiedades y territorios, de los cuales se lucran, y que, vale decir, fueron adquiridos con acciones non sanctas.

Según el Cinep (2013), la trayectoria de las luchas campesinas en el período 19882012, se ha caracterizado por una participación cada vez más acentuada de campesinos y pobladores rurales en situación de desplazamiento forzado, que muestra el máximo nivel en el año 1990 por la modificación de políticas para el agro (bajos precios e importación legal-ilegal de productos), donde estaba presente la reclamación de tierras, la violación de derechos humanos, daños generados por el conflicto armado, e infraestructura física precaria, servicios públicos y el crédito. 
En ese orden de ideas, Sarmiento, refiriéndose a la nueva arquitectura del bienestar en el siglo XXI, afirma que este es un debate que ocupa a todos y en esa discusión, "las desigualdades aumentan, los Estados se ocupan con mayor dificultad frente al masivo fenómeno de la exclusión, el trabajo se precariza y se torna más inestable, los hogares son más frágiles, vulnerables y efímeros, ya la distribución de los riesgos y de las necesidades sociales cambian dramáticamente" (Sarmiento, 2010).

En cuanto al eje de análisis, las desigualdades a nivel nacional y regional del campesino se han acentuado en el período 2006-2015 y no se prevé que puedan minimizarse en los tres años siguientes que se visionan (2018), porque cada vez le es más difícil obtener el sustento, cuando aproximadamente del 60,0\% de los productos que antes provenían del campo son importados y si a lo anterior se le añade la procedencia de los abonos y fungicidas (importados), la situación se torna más compleja. De la misma manera, el abandono del Estado cada vez es más evidente, porque a lo largo de los años se han diseñado políticas que favorecen en todo sentido a los medianos y grandes productores, a quienes les financian a largo plazo, bajos intereses y años de gracia, las actividades agropecuarias, mientras a los pequeños, que son la mayoría, les asignan montos de inversiones bajas que al distribuirlas por regiones no cumplen función alguna, lo cual se observa en los Conpes citados.

Por otra parte, el mismo autor (2010), refiriéndose al impulso dado por el Banco Mundial para transformar el sector social en América Latina bajo el enfoque de protección social, hace un replanteamiento en las áreas anteriores y retoma las tres estrategias para abordar ese riesgo ("prevención, mitigación y superación de eventos negativos, shocks), tres niveles de formalidad de manejo del riesgo (informal, mercado y público) y varios actores (personas, hogares, comunidades, ONG, diversos niveles de gobierno y organizaciones internacionales frente a un contexto de información asimétrica y distintos tipos de riesgo".

En la medida que el Estado desatiende las necesidades del campesinado, los problemas citados anteriormente se acentúan, porque ante la falta de apoyo (asesoría en producción, planeación, comercialización, distribución), este prefiere seguir cultivando lo que sabe y que le legaron sus ancestros, así sepa que va a tener pérdidas, porque necesita hacer algo y en su quehacer, después de cultivar se le imposibilita vender sus productos al consumidor directamente, por los múltiples canales que debe enfrentar, lo que hace encarecer el producto y él es el que menos recursos recibe.

En ese orden de ideas, al campesino no solo lo agobian las dificultades referidas, porque en zonas donde existen tierras fértiles o riquezas naturales están presentes las presiones que ejercen miembros de la guerrilla, paramilitares, delincuencia común, narcotraficantes, fuerzas privadas, aliados muchas veces con empresarios y fuerzas del Estado, generando desplazamiento de sus propiedades y más pobreza. Para 
reafirmar lo anterior, Sarmiento (2010) advierte que, "la pobreza se convierte en un negocio para quienes viven de ella (empresarios, políticos, Iglesias, organizaciones de la sociedad civil, organismos internacionales y multilaterales), por tanto, no están interesados en transformar el sistema que la genera".

A ese respecto, los poderosos se alían con el Estado, no para garantizar los derechos fundamentales, en este caso, de los campesinos, sino que oficializan su actuar al lado de los poderosos (palmicultores, trasnacionales, consorcios mineros y petroleros) y este procede, como lo ha hecho con los indígenas, a expropiar territorios con títulos ancestrales, desconociéndolos y atacándolos con la fuerza pública. Los indígenas son los únicos que a través de jurisprudencia están haciendo respetar sus derechos fundamentales, pero la respuesta es asesinar a sus líderes.

Es aquí cuando el Estado "es funcional a los grupos de poder y, en consecuencia, en el proceso de extensión de los DESCA (derechos económicos, sociales, culturales y ambientales) al servicio de los intereses privados, se presenta una metamorfosis de derechos en mercancías, con lo cual el capital amplía su campo de acción, a la vez que resuelve sus problemas de sobreacumulación. Los derechos quedan vaciados de contenidos, y el discurso sobre estos cumple la función enajenante de fetichizar al Estado y de controlar ideológica y políticamente a las masas empobrecidas y excluidas" (Sarmiento, 2010, p. 45).

La ampliación del campo de acción de los capitalistas tiene connotaciones que los favorecen, por el poder que han adquirido en las diferentes esferas del Estado, las cuales aprovechan para beneficiarse en el sistema de tributación, que se encarga de imponer gravámenes a los que menos tienen -en este caso, se incluye el campesinadoy aprueban exenciones y otros beneficios a los que más capital tienen, porque el Estado de garantizar los derechos fundamentales, obvia el cumplimiento de la justicia y la equidad.

Por otra parte, Fernández (2011), refiriéndose al desarrollo humano integral, afirma que este como política social "acoge y supera, las teorizaciones tradicionales sobre el "desarrollo": modernización de las estructuras políticas, educativas y productivas" (Kennan, 1998); "como superación de la dependencia" (Prebish, 1950); "como generación de sistemas mundiales en investigación, tecnología y comercio" (Wallestein, 1987); y "globalización como oportunidad para el desarrollo humano sostenible" (Sen, 1997).

Quiere decir el autor, y los demás en que se apoya, que esta generación tiene la posibilidad de superar los escollos que a lo largo del tiempo se han presentado, por la visión distorsionada y fragmentada con que se ha enfocado y aplicado el desarrollo, especialmente el humano, razón por la cual ante los múltiples fracasos de diversas 
teorías, es la hora de refundarlas y reconstruirlas para el logro del equilibrio humano, donde están presentes, por una parte, la necesidad de bienestar, del cual se carece y la justicia social, como exigencia.

Fernández (2011) se atreve a reconocer, que "la crisis internacional abierta a principios del siglo XXI vuelve a situar, en primer plano, la moralización de la economía como presupuesto de actuación de los poderes político-sociales (en los mercados financieros, en las relaciones de producción, en las acciones de empleo, en la lucha contra la pobreza o en la sostenibilidad medioambiental)".

En ese orden de ideas y compartiendo los argumentos de otros eruditos en la materia, el autor cuestiona la actuación de los países desarrollados o industrializados, bajo cuya tutela está el manejo de la economía del mundo, especialmente de los que están supeditados a ellos (países en vías de desarrollo o subdesarrollados), a la cual no se le ha dado un manejo moral y menos humano, porque son muchas las exigencias y condiciones que imponen a través de los organismos multilaterales de crédito, que están bajo su tutela, para otorgar empréstitos en dólares a los que más los necesitan, porque su precaria economía presenta un desfase por las necesidades sociales que los aquejan, frente a los ingresos que generan.

Es por ello, continúa Fernández, que

la riqueza mundial crece en términos absolutos, pero aumentan también las desigualdades. En los países ricos, nuevas categorías sociales se empobrecen y nacen nuevas pobrezas. En las zonas más pobres, algunos grupos gozan de un tipo de superdesarrollo derrochador y consumista, que contrasta con situaciones persistentes de miseria deshumanizadora, corrupción e ilegalidad. (2011)

La presencia de la desigualdad está vigente en el caso del campesinado colombiano, especialmente en el sector rural, donde la desidia del Estado ha permitido que este sea un sector que cada vez se empobrece más y donde la tradición enraizada en su quehacer ha contribuido en mantenerlo aletargado. De la misma manera, en este sector y en el resto de los habitantes, existe una creciente amoralidad en todo sentido, por el ambiente cautivo que promueven los medios de comunicación y que los medios tecnológicos de aplicar costumbres ajenas.

Antes de analizar desde el punto de vista jurisprudencial la concepción de la seguridad alimentaria, es importante referirse a las características concretas que tiene el campo como tal, catalogado por la misma Corte como bien jurídico de especial protección constitucional desde el Estado social de derecho, la visión globalista competitiva y desde la óptica de las libertades económicas, que deben existir en cada país. 
Para la Corte Constitucional (C 644/2012), la expresión campo

es la realidad geográfica, regional, humana, cultural y, económica, que por lo mismo está llamada a recibir una especial protección del Estado, por los valores que en sí misma representa. Es también, un conjunto de tierras destinadas a la actividad agropecuaria, el espacio natural de la población campesina, fuente natural de riqueza del Estado y sus asociados.

Por otra parte, el campo se cataloga como bien jurídico por la protección constitucional que le brindan los artículos 60, 64 y 66, 65 y 150, numeral 18 de la Carta, donde se expresa el valor constitucional específico y privilegiado de la propiedad rural y del campesino propietario. Respecto a la propiedad del campo, este es un derecho que el constitucionalismo colombiano desde la primera república liberal ha reconocido con las limitaciones y restricciones propias de su función social y ecológica.

En ese orden de ideas,

es el artículo 64 de la Carta el que contempla como deber del Estado garantizar el acceso a la propiedad de la tierra de los trabajadores agrarios, mandato que no sólo persigue asegurar un título de propiedad sino "mejorar el ingreso y calidad de vida de los campesinos", fin al que concurren otros elementos como el acceso a vivienda, tecnología, mercados, asistencia financiera y empresarial con miras a fortalecer su nivel de ingreso e incidir de esta manera en su "calidad de vida". (Corte Constitucional, sentencia C 644/2012).

Producto de la globalización de las relaciones económicas y la aplicación del derecho internacional que le corresponde al Estado colombiano en cuanto a los derechos humanos, se le ha dado la importancia que merece el acceso a la propiedad de los campesinos relacionándolo con el de la alimentación, como reza el artículo 11 del Pacto de Derechos Sociales, Económicos y Culturales que específicamente contiene lo atinente a la protección de toda persona contra el hambre, donde le corresponde a los Estados adoptar "medidas que se orienten al mejoramiento de los métodos de producción, conservación y distribución de alimentos mediante el perfeccionamiento o la reforma de los regímenes agrarios de modo que se logren la explotación y la utilización más eficaces de las riquezas naturales".

Es así como en el Informe del Relator Especial sobre el derecho a la alimentación de las Naciones Unidas de 11 de agosto de 2010, se señaló que "El acceso a la tierra y la seguridad de la tenencia son esenciales para asegurar el disfrute no solo del derecho a la alimentación, sino también de otros derechos humanos, incluido el derecho al trabajo (de los campesinos que no poseen tierras) y el derecho a la vivienda", concluyendo luego que el Consejo de Derechos Humanos debía "garantizar el 
reconocimiento de la tierra como un derecho humano en el derecho internacional relativo a los derechos humanos" (...)".

A la par con lo establecido en la Constitución Política de 1991, el artículo 65 constitucional expresa que 1) la "producción de alimentos gozará de la especial protección del Estado" 2) que se debe otorgar "prioridad al desarrollo integral de las actividades agrícolas, pecuarias, pesqueras, forestales y agroindustriales", 3) de igual manera que "a la construcción de obras de infraestructura física y adecuación de tierras" y que 4) todo ello debe dirigirse a "incrementar la productividad" además de promover "la investigación y la transferencia de tecnología para la producción de alimentos y materias primas de origen agropecuario (...)" (Corte Constitucional, sentencia C 644 de 2012).

La anterior es una disposición que está orientada a salvaguardar la producción, a fin de asegurar la seguridad alimentaria, a la vez que le da relevancia al desarrollo integral del sector agropecuario, por lo que se deduce que por mandato constitucional, lo concerniente a lo agrario amerita hacer parte de la agenda pública del Estado colombiano. El apoyo, en este caso, ha de ser integral (mejora del proceso productivo y la eficiente explotación de la tierra, sin descuidar la reducción de las extremas desigualdades y consiguiente mejora de las condiciones de vida de la población campesina), (Corte Constitucional, sentencia C 644/2012).

En este orden de ideas, en la sentencia T-348 de 2012, de la Corte Constitucional, se reconoce

el derecho a la seguridad alimentaria tanto a partir del artículo 64 superior al proteger a los campesinos su derecho de acceder a la propiedad de la tierra que trabajan, como a partir de los artículo 65 y 66 al incluir como opción posible en la regulación crediticia el reglamentar "condiciones especiales del crédito agropecuario, teniendo en cuenta los ciclos de cosechas y de los precios, como también los riesgos inherentes a la actividad y las calamidades ambientales". Por último, se reconoce también a partir del artículo 78 superior, al reconocer como posiciones jurídicas fundamentales de los derechos del consumidor, el control de calidad de los bienes y servicios ofrecidos y prestados a la comunidad, y la responsabilidad en todo caso en que se produzcan y comercialicen bienes y servicios que, "atenten contra la salud, la seguridad y el adecuado aprovisionamiento a consumidores y usuarios".

Vale recordar que el derecho a la seguridad alimentaria ha sido acogido, concebido y establecido como obligación para los Estados en declaraciones de Naciones Unidas, como la Declaración Universal de Derechos Humanos (art. 25), la Declaración Universal sobre la Erradicación del Hambre y la Malnutrición de 1974, la Declaración 
Mundial sobre la Nutrición de 1992, Declaración de Roma sobre la Seguridad Alimentaria Mundial de 1966 e igualmente en la Resolución 2004/19 de la Asamblea General. Así mismo, la organización especializada en alimentación y agricultura derivada de Naciones Unidas, la Organización para la Alimentación y la Agricultura -conocida por su sigla en inglés FAO-, a tal punto que en el Plan de Acción de la Cumbre Mundial sobre la Alimentación (FAO, noviembre de 1996), se declaró que la seguridad alimentaria "a nivel individual, familiar, nacional, regional y mundial, se alcanza cuando todas las personas tienen en todo momento acceso físico y económico a suficientes alimentos inocuos y nutritivos para satisfacer sus necesidades al imenticias y sus preferencias en cuanto a los alimentos a fin de Ilevar una vida activa y sana" (ONU \& FAO, 2010).

Como norma de carácter general, se consignó en el Pacto Internacional de Derechos Económicos Sociales y Culturales (PIDESC) que consagra en su artículo 11.1, el deber de los Estados de reconocer a toda persona una calidad de vida adecuada incluyendo una sana alimentación y el derecho fundamental de toda persona a ser protegida contra el hambre. En sentido semejante se consignó en el Protocolo adicional a la Convención Americana sobre Derechos Humanos en materia de Derechos Económicos, Sociales y Culturales, Protocolo de "San Salvador", de 1988 (artículo 12).

En relación con su importancia, el Comité de Derechos Económicos, Sociales y Culturales de Naciones Unidas, como intérprete principal del alcance del PIDESC, en su Observación General No. 12, señala que el derecho a la alimentación adecuada se ejerce "cuando todo hombre, mujer o niño, ya sea sólo o en común con otros, tiene acceso físico y económico, en todo momento, a la alimentación adecuada o a medios para obtenerla" y a la vez precisó, que "el derecho a la alimentación tiene cuatro aristas: 1) la disponibilidad, 2) la accesibilidad, 3) la estabilidad y 4) la utilización de los alimentos".

Resultado de lo anterior, aparece el derecho a la seguridad alimentaria, cuya existencia "se puede reconocer como la dimensión colectiva del derecho de todos a la alimentación adecuada, suficiente y de calidad, y también como el derecho de cada uno a acceder a los alimentos que satisfagan las necesidades y la calidad de vida digna de todo sujeto". Para que se dé esta realidad, el Estado colombiano ha de fijar una política pública y comunitaria ajustada a las necesidades reales del campesinado, con el fin de asegurar la existencia y disponibilidad de alimentos a las generaciones de hoy y a las del mañana.

Así mismo, en la Cumbre Mundial sobre la Alimentación en 1996, la FAO introdujo el concepto de soberanía alimentaria,

como derecho de cada pueblo a definir sus propias políticas y estrategias sustentables 
de producción, distribución y consumo de los alimentos que garanticen una alimentación sana. Lo anterior, con base en la pequeña y mediana producción, respetando sus propias culturas y la diversidad de los medios campesinos, pesqueros, étnicos e indígenas de producción agropecuaria, comercialización y gestión de recursos. La seguridad y la soberanía alimentaria, son dimensiones objetiva o institucional y colectiva del derecho fundamental de alimentarse adecuadamente. (Corte Constitucional, Sentencia T 344/2012)

La Corte Constitucional en su jurisprudencia ha dicho que del artículo 65 se desprende el concepto de seguridad alimentaria y que

(...) se vulnera el deber de seguridad alimentaria reconocido en el artículo 65 del Texto Superior, cuando se desconoce el grado de garantía que debe tener toda la población, de poder disponer y tener acceso oportuno y permanente a Ios alimentos que cubran sus requerimientos nutricionales, tratando de reducir la dependencia externa y tomando en consideración la conservación y equilibrio del ecosistema para beneficio de las generaciones futuras.

En esta misma perspectiva, la sentencia T-348 de 2012, de la Corte Constitucional, hace referencia al concepto de soberanía alimentaria en comunidades vulnerables, desde la perspectiva de las comunidades rurales que subsisten del cultivo, producción y distribución de alimentos obtenidos de la naturaleza, y en particular señala:

La soberanía alimentaria, comprende, no sólo la libre potestad de los Estados y los pueblos de determinar sus procesos de producción de alimentos; también implica que esos procesos de producción garanticen el respeto y la preservación de las comunidades de producción artesanales y de pequeña escala, acorde con sus propias culturas y la diversidad de los modos campesinos y pesqueros.

Respecto a la definición del término derechos fundamentales y cuáles son, Ferrajoli (2007), fija tres criterios axiológicos: a) el primero de ellos indica que existe entre "derechos humanos y paz", partiendo de la Declaración Universal de 1948. En este caso, afirma que todos los derechos que se relacionan con la paz y para su logro, deben garantizarse como tal (a la vida, los civiles y políticos, la libertad y los sociales o prestacionales necesarios para garantizar adecuados niveles de calidad de vida). b) El segundo está conformado por la relación entre derechos, igualdad y diferencias culturales. Afirma el autor que en la igualdad de derechos, a nadie debe discriminársele y que en el caso de las desigualdades sociales, el Estado tiene la obligación de reducir las diferencias socioeconómicas existentes, a través de políticas encaminadas para la búsqueda de esa equidad. c) El tercer criterio se refiere al rol que cumplen los derechos fundamentales, como leyes del más débil. En ese orden de ideas, todos los derechos que entran en la categoría de fundamentales, son leyes que le permiten al 
ciudadano más débil o desamparado enfrentar la ley de los que más tienen y que por lo tanto son fuertes (monopolios de salud y pensiones). Ejemplos de ellos, son los millones de tutelas que se impetran por parte de los colombianos en un año para tener acceso a la salud, como lo establece la Constitución Política de Colombia de 1991; las de personas que tienen derecho a la pensión y no se les reconoce a pesar de tener avanzada edad y han cotizado toda su vida para hacerlo.

Las autoras González Sánchez y Duque Quintero (2008, p. 25) retoman la jurisprudencia sobre la protección del derecho a la subsistencia de las comunidades locales en Colombia (indígenas, afrocolombianos y campesinos), seleccionando y analizando las principales providencias de los años 1992-2006 de la Corte Constitucional y del Consejo de Estado, para lo cual construyen una línea jurisprudencial, "utilizando el método de análisis dinámico de precedente, propuesto por el profesor Diego López Medina, en el cual desde una "ingeniería de reversa de la línea", se determinan las sentencias hito, las sentencias fundadoras y las sentencias confirmadoras de jurisprudencia". En ese sentido, Shue (1996, citado por González \& Duque, 2008, p. 27) afirma que este derecho significa "no sólo el derecho a un mínimo de comida, sino el derecho a respirar aire limpio, a beber agua potable, a un mínimo de educación, de vivienda, de ropa y de salud que garanticen un nivel mínimo de subsistencia". En síntesis, incluye todos los derechos fundamentales de los campesinos colombianos que son afectados por la apatía, abandono del Estado y la práctica de políticas incompletas y erróneas.

En ese orden de ideas, para Rojas (2012),

Colombia es un país que puede considerarse blindado en cuanto a la protección del medio ambiente puesto que cuenta con los instrumentos jurídicos necesarios para ello. Ha suscrito los principales tratados y convenios internacionales aprobados por el Congreso de la República muchos de los cuales han sido revisados en su constitucionalidad por la Corte Constitucional, contando además con normas que constituyen verdaderos estatutos de protección del medio ambiente como el Decreto 2811 de 1974 que contiene el Código de Recursos Naturales producto de la Declaración de Estocolmo de 1972 y la Ley 99 de 1993 luego de la Cumbre de la Tierra Ilevada a cabo en Rio de Janeiro en 1992 y finalizando con la jurisprudencia tanto de la Corte Constitucional al revisar los tratados internacionales o al ejercer el control abstracto de constitucionalidad, así como de la justicia contencioso administrativa tanto mediante las acciones populares o las acciones de nulidad al estudiar en concreto la legalidad de alguna disposición.

Por otra parte, se afirma que todos los informes ilustran la gradual convergencia entre la guerra y el problema agrario (despojos violento, concentración ociosa de la 
tierra, usos inadecuados, colonizaciones y titulaciones fallidas). Pero a los viejos problemas se suman otros nuevos, que muestran las dinámicas inauguradas por el narcotráfico, la explotación minera y energética, los modelos agroindustriales y las alianzas criminales entre paramilitares, políticos, servidores públicos, élites locales económicas y empresariales, y narcotraficantes.

Son justamente estos anhelos de vida digna y justicia económica y social, los que se expresaron para el año 2013, pero cansados de que el Gobierno nacional no les atendiera sus peticiones y agobiados cada vez más por las crisis económica, los problemas brotaron como arroz en el campo colombiano, donde pocas veces se había registrado un año con tantas complejidades y dificultades para el sector. Sin embargo, paradójicamente, el 2013 fue un año de crecimiento, uno de los más altos en los últimos tiempos para la actividad agropecuaria. En el segundo trimestre fue el sector económico con mejor desempeño dentro del producto interno bruto (PIB).

\section{Conclusiones}

En el diagnóstico del sector agropecuario en Colombia se retoman los antecedentes de la problemática desde la óptica de las políticas económicas, teniendo en cuenta los argumentos neoliberales y de apertura económica, concluyendo que estas en nada han contribuido desde mucho antes del año 2006, a solucionar los problemas del sector agropecuario, pues, por el contrario, los han acentuado. Lo cual se sustenta en las diez brechas que Planeación Nacional detectó como consecuencia de la grave crisis que los afecta (pobreza y servicios públicos; envejecimiento y migración; ingresos insuficientes; caos en la propiedad; rezago y tradición; monoexportadores: café; política pública incipiente; limitaciones en la comercialización; ausencia de financiación; desastres naturales e imprevistos).

A la par con lo expuesto, la ONU, en buena hora, ha aprobado los derechos de los campesinos, los cuales se refuerzan por los derechos fundamentales de la Constitución Política de 1991, la jurisprudencia indígena que también los ampara, porque a la luz del derecho internacional, por más de cincuenta años de guerra se les han violado flagrantemente sus garantías y los "nuevos" por decirlo así, contradicen las políticas del Estado y la fragilidad con que atiende este delicado problema.

En lo atinente a la política agraria nacional y regional, contenida en los planes de desarrollo del mismo orden y en los Conpes, la literatura de los mismos contradice la realidad que afronta el sector agropecuario en Colombia, como se muestra en los diez cuellos de botella detectados por el Departamento de Planeación Nacional, que comprueban la gravedad del problema. En el caso de los nueve Conpes, estos muestran un perfilamiento hacia las grandes asociaciones de agricultores, que utilizan tecnologías duras y blandas en sus procesos y excluyen al pequeño y mediano agricultor. 
En cuanto a los derechos humanos de los agricultores boyacenses, estos de igual manera han sido violados, porque las acciones lesivas del Estado, al importar más del $30,0 \%$ de los productos agropecuarios de vocación boyacense, ha generado una masiva migración del campo hacia Bogotá, especialmente, donde la población joven tiene la mayor representatividad.

En lo que respecta a la situación agropecuaria del departamento de Boyacá y el paro agrario, los campesinos de esta zona se han caracterizado por ser pacíficos por excelencia, sin embargo, al ver cómo el Estado ha promovido y patrocinado su ruina y las de sus familias, decidieron actuar como hace más de veinte años, con fuerza y entereza para defender los derechos fundamentales violentados. La vocación agrícola de la región, dependiente de la papa y de los cultivos complementarios, ha afectado con mayor énfasis a los agricultores, donde el paro permitió grandes logros como el estudio y la búsqueda de soluciones a los altos costos de producción, la protección de medidas al comercio local, y acciones en contra del contrabando, caso de la Resolución 970 y Mesa de Interlocución Agraria -MIA- del Gobierno nacional.

Entre los avances están la instalación y operación de las mesas temáticas en crédito y financiamiento, cereales, comercio, insumos (esta mesa opera a través de la comisión intersectorial de insumos), medio ambiente, minería y asociatividad, todas las mesas están activas y avanzan con participación del Gobierno nacional y los voceros de los campesinos.

Es importante no dejar de lado el alcance que han tenido los movimientos campesinos de los años 2013 y 2014, consistente en el Pacto Agrario como una oportunidad histórica para la ruralidad colombiana, con la que se permitirá construir la política de Estado para el agro, que se enfoque a favorecer los derechos de los campesinos, dignificando su trabajo, y que sea territorial, es decir, que construya consensos regionales de política desde las regiones mismas hacia el centro, y no al revés.

Por otra parte, el campo no puede ser reconocido únicamente como un área geográfica ordenada por regímenes distintos de autoridades nacionales o locales, por derechos de propiedad privada, posesiones, ocupaciones, planes de ordenamiento territorial y por tierras baldías que administra el Estado. En cambio, debe ser entendido dentro de su especificidad como bien jurídico protegido para garantizar derechos subjetivos e individuales, derechos sociales y colectivos, así como la seguridad jurídica, pero además, es herramienta básica de la pervivencia y el progreso personal, familiar y social.

EI Pacto Agrario es un proceso de construcción participativa propuesto por los campesinos e institucionalizado por el Gobierno nacional de la mano de las entidades 
territoriales, los actores del sector agropecuario y demás organizaciones campesinas y de productores, con el fin reformular la política pública de desarrollo rural. El Pacto Agrario se convirtió en el más amplio e incluyente ejercicio de participación que se haya puesto en marcha en la historia reciente de Colombia para la construcción de una política de Estado para el sector agropecuario y rural. Está Ilamado a permanecer en el tiempo como un mecanismo de discusión y consulta sobre los principales aspectos relacionados con el desarrollo rural, institución que el sector agrario no debe desaprovechar.

Colombia tiene una normativa sustancial y sólida como es la Constitución Política de 1991, catalogada como "ecológica" por la variedad de garantías que en materia ambiental ofrece a sus habitantes. Sin embargo, contempla de igual manera deberes y obligaciones para quienes pretendan degradar o atacar la biodiversidad, mediante leyes, decretos, resoluciones documentos Conpes, jurisprudencia (Corte Constitucional, Consejo de Estado) en el ámbito nacional, y en el derecho internacional a través de las ratificaciones que ha realizado el Estado colombiano de los tratados y pactos. En ese orden de ideas, no es por falta de normas que se presentan delicadas falencias y abusos en el otorgamiento de licencias ambientales.

Es común la violación de los derechos fundamentales de los colombianos con la intervención de los ecosistemas para explotación minera, petrolera, hidroeléctrica, maderable o agropecuaria, sin la realización de estudios de impacto ambiental -EIAque no cumplen con la rigurosidad académica, con consecuencias desastrosas como sequías, inundaciones, agotamiento o envenenamiento de agua potable, derrumbes, avalanchas, epidemias, plagas, agotamiento y esterilidad de los suelos, agotamiento de la pesca, etc.

Existe, de igual manera, desconocimiento de las negritudes y de los territorios indígenas; en las zonas petroleras prolifera la prostitución y las enfermedades de transmisión sexual, y el costo de la vida es cada vez mayor en la región. Las regalías se utilizan para asuntos distintos a los que la ley las destinó. Así mismo, la deforestación causa sequía en las tierras, los campesinos pierden sus cultivos, y las grandes explotaciones mineras desplazan población oriunda de esas tierras. Las épocas de sequía se hacen más largas y severas, con la consecuencia de la destrucción de la fauna y la flora, que acaba con ecosistemas. $Y$ las licencias ambientales se han convertido en un fortín político. Por lo tanto, la actitud que deben seguir los habitantes residentes en el entorno de las zonas afectadas en defensa de los derechos ambientales, es actuar mancomunadamente con las comunidades indígenas.

Por último, es importante insistir que la mayor responsabilidad recae en los electores, quienes deben escoger votar por amigos y no por enemigos. 


\section{Referencias}

Departamento Nacional de Planeación -DNP-. (2015). Misión para la transformación del campo colombiano. Bogotá. Recuperado de http://www.pnud.org.co/ hechosdepaz/64/la_declaracion_de_naciones_unidas.pdf

Departamento Nacional de Planeación -DNP-. (2007, 29 de ene.). Conpes 3458 Política Nacional de Sanidad e Inocuidad para la Cadena Porcícola. Bogotá: DNP.

Fernández R, S (2011). Política social y desarrollo humano. La nueva cuestión social del siglo XXI. Madrid: Nómadas.

Ferrajoli, L. (2007). Teoría del neoconstitucionalismo. Madrid: Trotta.

Garay, L. J. (2009). Colombia: estructura industrial e internacionalización 19671996. S.I.: s.n.

González, P. \& Duque, S. P. (2008). Subsistencia de las comunidades locales en Colombia. De un concepto legal a un derecho fundamental. Análisis jurisprudencial. Medellín: Colciencias.

Robledo, J. E. (2015). Problemas del sector agropecuario. Bogotá: Senado de la República, Audiencia pública.

Rojas, M. C. (2012). La protección jurisprudencia del medio ambiente en Colombia. Bogotá: s.n.

Sarmiento, L. (2010). Derechos humanos, democracia, desarrollo y políticas públicas. En Teoría crítica de los derechos humanos. Maestría UPTC (p. 37). Tunja: Salamandra.

Universidad Pedagógica y Tecnológica de Colombia -UPTC- (2015). Maestría de Derechos Humanos: misión, objetivos. Tunja: UPTC. 